\title{
THEORETICAL RESEARCH REGARDING THE RISK-FREE WORK OF THE GANTRY CRANES
}

\author{
GHEORGHE N. RADU ${ }^{1}$, IOANA SONIA COMĂNESCU ${ }^{2 *}$ \\ ${ }^{I}$ Transilvania University of Brasov, ROMANIA, 500036 Brașov, B-dul Eroilor nr.29, \\ Department of Mechanical Engineering \\ ${ }^{2}$ Transilvania University of Brasov, ROMANIA, 500036 Brașov, B-dul Eroilor nr.29, \\ Department of Engineering and Management in Food and Tourism
}

\begin{abstract}
The research bases on the observation that the check imposed by the National Authority I.S.C.I.R. regarding the cranes authorization is necessary but not enough for the assurance of their work safety. The current specific rules do not contain provisions concerning the vibratory state of the cranes. Practice shows that the beginning of a work which is outside the normal parameters (changes of the optimum technical state - risk of accidents occurrence), appear in their vibratory mark. The research has as main goal the increase of the work safety and the elimination of the risk of accidents.
\end{abstract}

Keywords: crane, work safety, risk, accident, vibratory state

\section{INTRODUCTION. SIGNIFICANCE OF THE RESEARCH}

The need of cranes is extremely wide and various. The topicality and the significance of the gantry cranes study occur from the perspective of a special structure's analysis; it is about a 3D structure, consisting mainly of beams, which is loaded under static and dynamic conditions. A particular request for this structure is the assurance of the work safety.

The risk of accidents occurrence is major. Figure 1 shows the portal crane no. 191/19690 - CRAIOVA, within the validity period of the operating license, which underwent a serious accident, being destroyed in proportion of $80 \%$ (as shown in Figure 2).

For the calculation, designing and check of the gantry cranes truss, the current normative contain theoretical and experimental tests, generally based on classical strength calculations, on the basis concepts of the elasticity theory, but also on modern techniques, using specific software (ANSYS, NASTRAN, FTOOL, ABAQUS, etc.). The current specific normative do not contain provisions concerning the vibratory state of the cranes. Practice shows that the beginning of the work which is outside the normal parameters (changes of the optimum technical state - risk of accidents occurrence), appear in their vibratory mark.

The author set a consistent conclusion regarding the assurance of the cranes' operating safety: the current normative do not approach issues concerning the vibratory state. The authors ascertain that the first signs regarding a bad work and so the risk of accidents is emphasized in the vibratory mark of the structure. The frequency answer functions provide an efficient estimation method, through compound techniques (both

\footnotetext{
*Corresponding author, email: ioanacom@unitbv.ro

(C) 2015 Alma Mater Publishing House
} 
theoretical and experimental) [1]. The experimental structure analysis is applied in tandem with the FEM theoretical analysis. FEM must use a mathematical model, likely to the experimental one.

The performed studies (theoretical and experimental research) have as a main goal, the increase of the work safety and the elimination of the accidents risks. It has to be noted that the activity area of the cranes coincides with some activity zones of the workers.

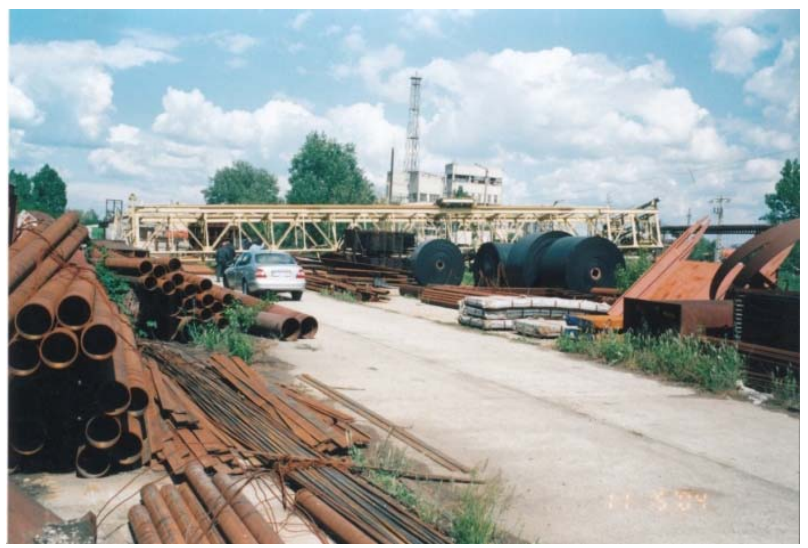

Fig. 1. The crash of the crane.

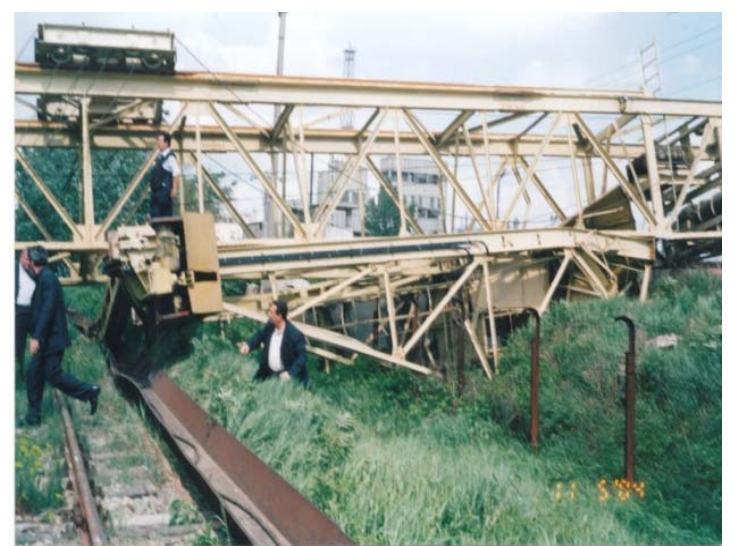

Fig. 2. The crash of the crane. Detail.

At the work safety basis stands the accurate knowledge through adequate techniques and technologies of the whole structure and of its components state of stress, of the structure's answer in static and dynamic conditions, expressed mainly through the values of the strains and stresses field.

Through the accomplished studies one aims, the precise knowing of the working under static and dynamic load of the gantry cranes and taking into account the required actions for the work safety, in order to avoid the risk of accidents.

The richness of the experimental data, the yielded results and the formulated conclusions ensures the profoundness and the credibility of these studies, given by the engineering's supreme criterion - the experiment. One emphasizes that the experimental tests have been performed with adequate high performance, equipment and installations, recognized in the field of mechanical engineering area.

\section{THEORETICAL STUDIES}

The approach is definite on the constructive components, depending on the load; one achieves strength calculations for the elements subjected to traction, to compression, to buckling and to bending. One considers the full - heart beam structures (regarding the construction, the stress and strain calculation) - trusses, the wheels and cable calculation. The calculation of the main beam is performed in two ways of the ends connection: (single supported and both ends fixed supported); the load is a concentrated force which acts in the middle of the beam's span and an uniform distributed force along its length. One plots the diagrams and conclusions are formulated. The strength calculation for the load's lifting device is also performed. More cross section shapes were considered. One starts with the mechanical and geometrical input data, one proceed to the determination of the lifting device engine's power, to the shifting device's and to the crane's hook calculation [2].

The theoretical analysis of the gantry cranes state of stress and strain is based on modern numerical methods the Finite Elements Method (FEM). One uses ABAQUS software, an advanced one, with highly efficiency and accuracy modelling possibilities. The use of this software was achieved for analysis of the functional model which collapsed under usual operating conditions. The modelling was achieved for the entire structure (Figure 3 ), but the considered main element is the main beam, I - shape cross section with the $42 \times 80 \times 2660 \mathrm{~mm}$ dimensions, reinforced by a truss. A number of 2818 3D Beam elements were used. Two types of cranes were studied: cranes with and without wing bracings [3].

By graphical post processing the equivalent von Mises stresses and strains field are shown; the same stresses and strains (vertically achieved) registered in seven points (P1, P2, ..., P7). 


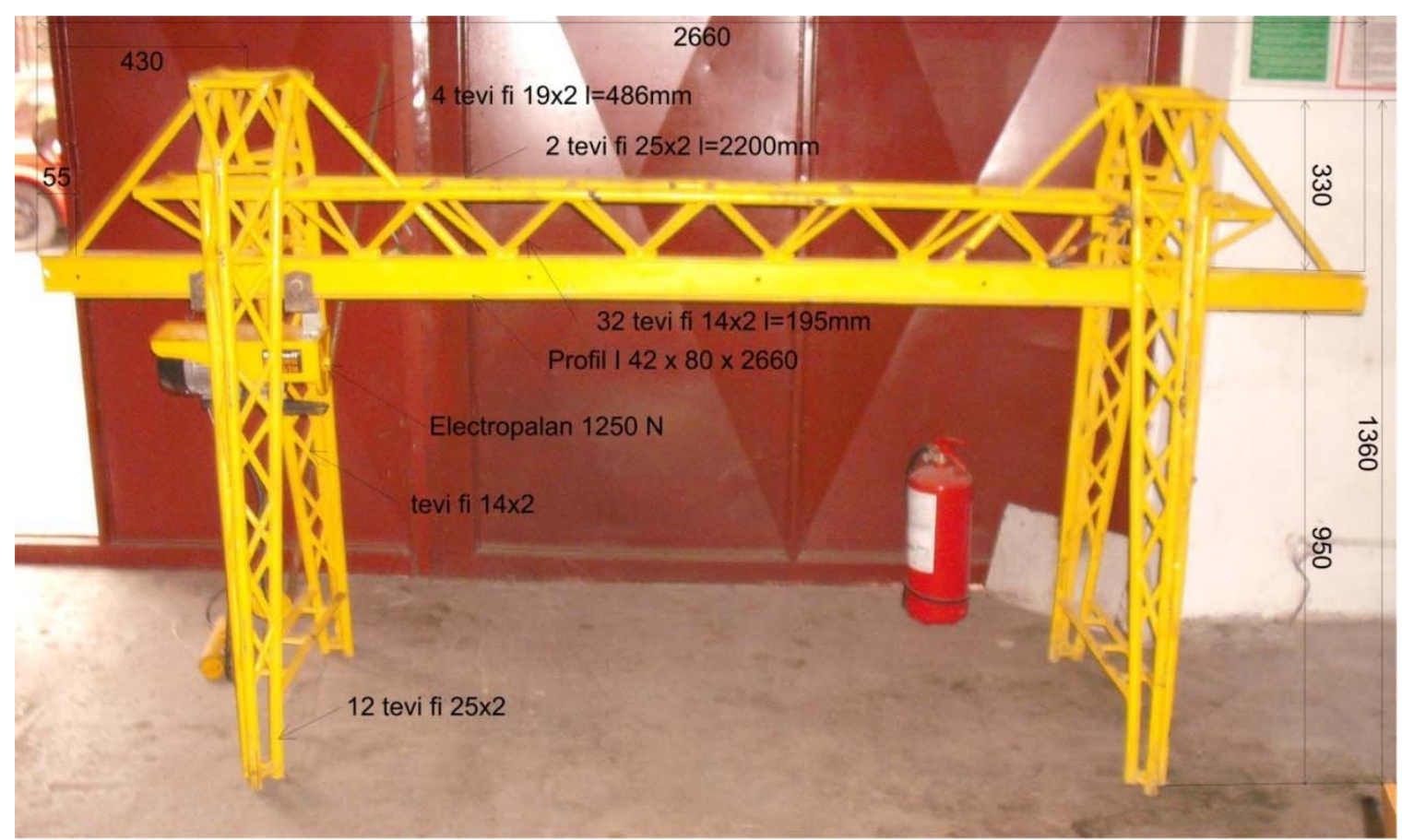

Fig. 3 Pattern of the gantry crane, scale 1/10.

All the determinations are performed for three loading ways, with a concentrated force placed successively in three points.

The authors aim to study the elastic structure of the gantry crane, based on similarity criteria, in whose purpose Hook and Cauchy's criteria were used. The concept of similarity was used meaning that the study methodology on the model way be extended to any other dimensions of the crane.

\section{Components:}

- Main beam, I 42×80x2660 [mm] profile, reinforced through a truss;

- The crane's feet, made up of 1" tubes, $2 \mathrm{~mm}$ wall thickness, reinforced by a truss manufactured of $1 / 2$ " tube, $2 \mathrm{~mm}$ wall thickness;

- Electric hoist which slides along the main beam.

\subsection{The classic strength calculus of the main beam}

\subsubsection{Both Ends Supported Beam}

Both ends fixed beam calculated using conventional methods are presented in Figures 4 and 5 . Values obtained using strain gauges are also shown in critical points.

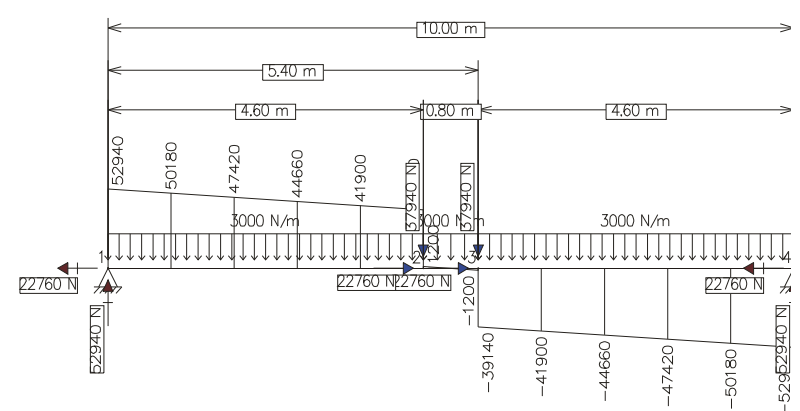

Fig. 4. Shearing forces diagram.

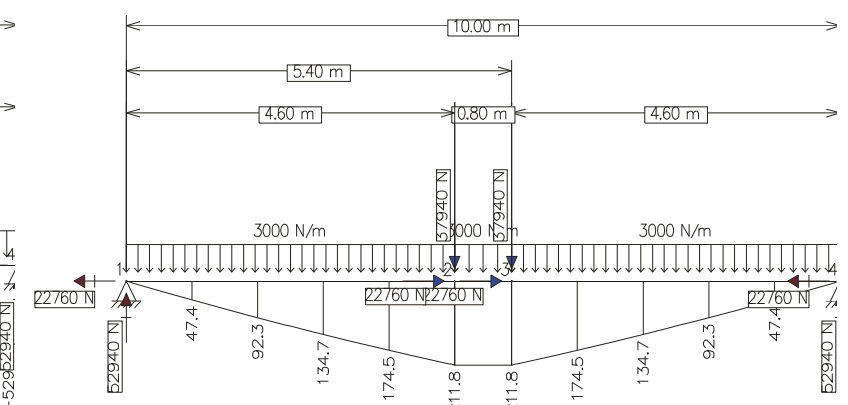

Fig. 5. Bending moments diagram. 


\subsubsection{Both Ends fixed rigid Beams}

For the classical diagrams used in strength of materials a bigger importance has the bending moment and the share stress diagrams. In Figures 6 and 7 those two diagrams are shown, while the general bending solicitation is shown in Figure 8.

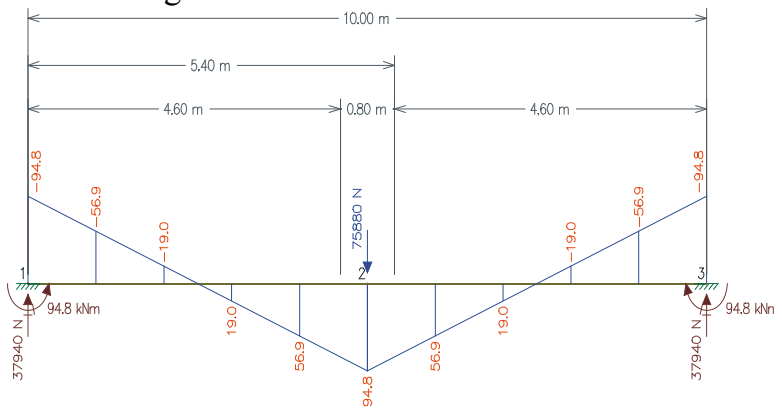

Fig. 6. Concentrated forces. Bending moments diagram.

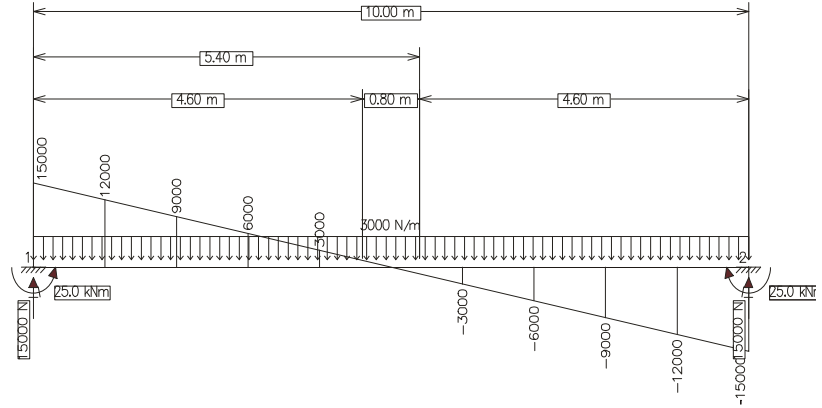

Fig. 7. Distributed forces. Shearing forces diagram.

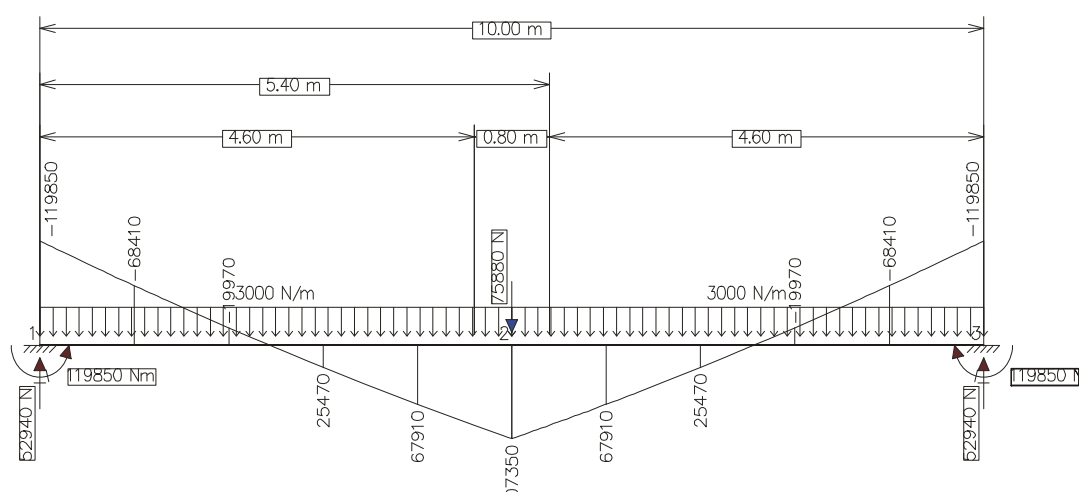

Fig. 8. Distributed forces. Bending moments diagram [4].

\subsection{FEM analysis of the crane, using ABAQUS software}

One developed a mathematical model of the crane using a number of 2818 elements of Beam 3D type (Figure 9). The basic element is the main beam, manufactured of an "I" profile, reinforcing the truss. Two constructive variants are studied: with and without wind-bracings (Figure 10).

Through the graphic processing the equivalent stresses field von Mises and the strain field are presented. The stresses and the vertical displacements in seven points of the main beam are tabular emphasized.

The comparative analysis of the results underlies the author's final conclusions, according to which the behaviour of the crane with wind-bracings is better, safer than of the one without wind-bracings ( Figure 10.b).

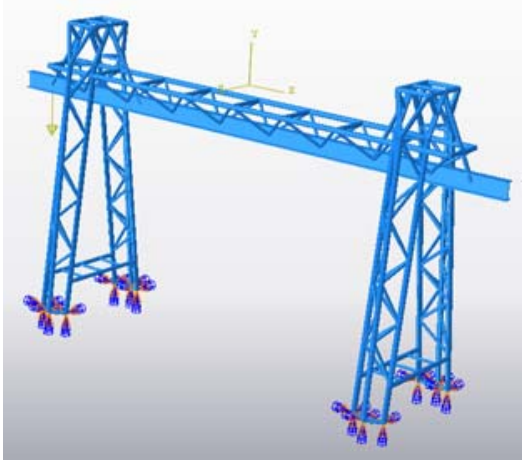

Fig. 9. Geometrical model of the crane. Applied load of 1444 N [4]. 


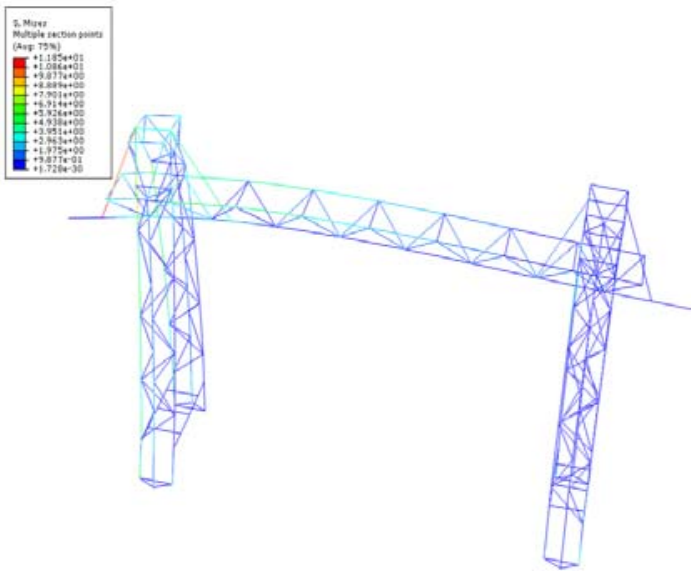

a)

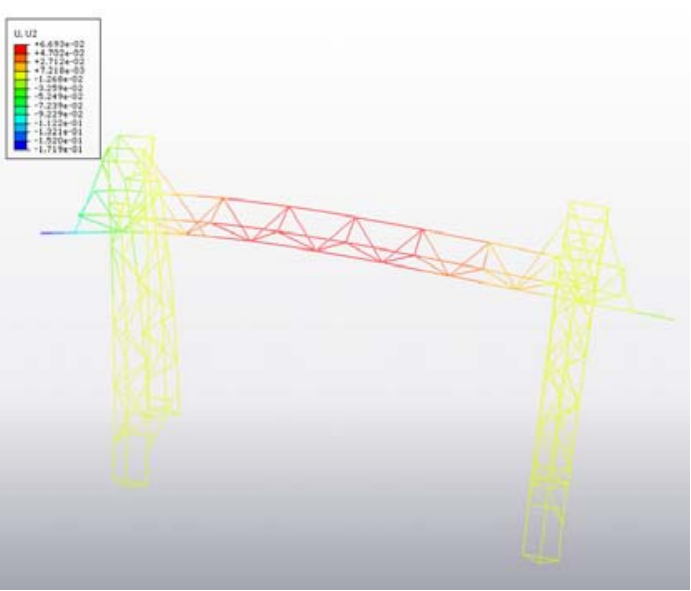

b)

Fig. 10. Stresses and strains for the load shown in Fig. 9.

In the Table 1 Stresses and strains for the load in points P1, P3, P4 values are shown. After running the FEM analyses the values of the equivalent stress calculated using von Mises criteria are shown in Figure 10.a and in Figure 12 the values of the displacement is shown.

Table 1 Stresses and strains for the load in points P1, P3, P4.

\begin{tabular}{|c|c|c|c|c|c|c|c|c|c|c|c|c|c|c|}
\hline \multirow{3}{*}{$\begin{array}{l}\text { Load } \\
\text { Points }\end{array}$} & \multicolumn{14}{|c|}{ Points analysis } \\
\hline & \multicolumn{2}{|c|}{ P1 } & \multicolumn{2}{|c|}{ P2 } & \multicolumn{2}{|c|}{ P3 } & \multicolumn{2}{|c|}{ P4 } & \multicolumn{2}{|c|}{ P5 } & \multicolumn{2}{|c|}{ P6 } & \multicolumn{2}{|c|}{ P7 } \\
\hline & $\begin{array}{c}\mathrm{Si} \\
(\mathrm{MPa})\end{array}$ & $\begin{array}{c}\mathrm{S} \\
(\mathrm{mm})\end{array}$ & $\begin{array}{c}\mathrm{Si} \\
(\mathrm{MPa})\end{array}$ & $\begin{array}{c}\mathrm{S} \\
(\mathrm{mm})\end{array}$ & $\begin{array}{c}\mathrm{Si} \\
(\mathrm{MPa})\end{array}$ & $\begin{array}{c}\mathrm{S} \\
(\mathrm{mm})\end{array}$ & $\begin{array}{c}\mathrm{Si} \\
(\mathrm{MPa})\end{array}$ & $\begin{array}{c}\mathrm{S} \\
(\mathrm{mm})\end{array}$ & $\begin{array}{c}\mathrm{Si} \\
(\mathrm{MPa})\end{array}$ & $\begin{array}{c}\mathrm{S} \\
(\mathrm{mm})\end{array}$ & $\begin{array}{c}\mathrm{Si} \\
(\mathrm{MPa})\end{array}$ & $\begin{array}{c}\mathrm{S} \\
(\mathrm{mm})\end{array}$ & $\begin{array}{c}\mathrm{Si} \\
(\mathrm{MPa})\end{array}$ & $\begin{array}{c}\mathrm{S} \\
(\mathrm{mm})\end{array}$ \\
\hline P1 & 0 & -0.13 & 2.9 & -0.07 & 1 & 0.047 & 0.5 & 0.066 & 0.25 & 0.008 & 0.1 & -0.01 & 0 & -0.07 \\
\hline $\mathrm{P} 3$ & 0 & 0.077 & 0.65 & -0.06 & 1.94 & -0.1 & 0.6 & -0.14 & 0.3 & -0.08 & 0.05 & -0.05 & 0 & 0.03 \\
\hline $\mathrm{P} 4$ & 0 & 0.95 & 0.175 & -0.05 & 1.5 & -0.13 & 4.5 & -0.22 & 1.5 & -0.13 & 0.175 & -0.05 & 0 & 0.95 \\
\hline
\end{tabular}

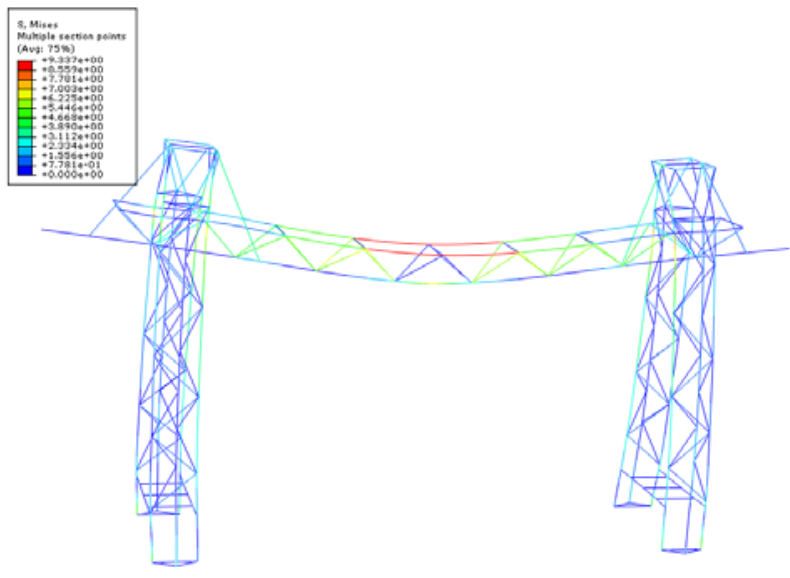

Fig. 11. Stresses and strains, crane with wind-bracings, applied load in P4 [4].

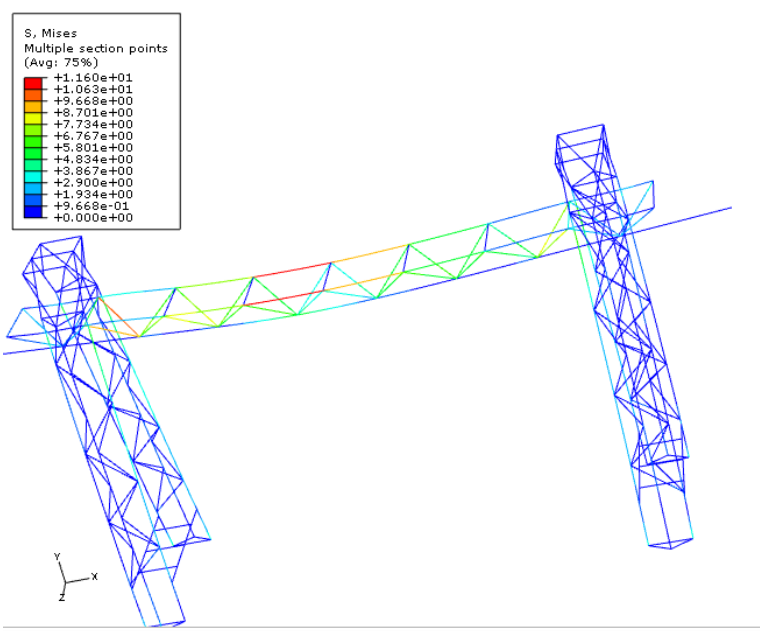

Fig. 12. Stresses and strains for the crane without wind-bracings. Applied load in P4 [4].

In the Table 2 Stresses and strains values for the crane with and without wind-bracings, load located in P4 are shown. After running the FEM analyses the values of the equivalent stress calculated using von Mises criteria are shown in Figure 11 and in Figure 12. 
Table 2. Stresses and strains. Crane with and without wind-bracings. Load located in P4.

\begin{tabular}{|c|c|c|c|c|c|c|c|c|c|c|c|c|c|c|}
\hline \multirow{3}{*}{$\begin{array}{c}\text { Crane } \\
\text { type }\end{array}$} & \multicolumn{14}{|c|}{ Points analysis } \\
\hline & \multicolumn{2}{|c|}{$\mathrm{P} 1$} & \multicolumn{2}{|c|}{ P2 } & \multicolumn{2}{|c|}{ P3 } & \multicolumn{2}{|c|}{ P4 } & \multicolumn{2}{|c|}{ P5 } & \multicolumn{2}{|c|}{ P6 } & \multicolumn{2}{|c|}{ P7 } \\
\hline & \begin{tabular}{|c}
$\mathrm{Si}$ \\
$(\mathrm{MPa})$
\end{tabular} & $\begin{array}{c}\mathrm{S} \\
(\mathrm{mm})\end{array}$ & $\begin{array}{c}\mathrm{Si} \\
(\mathrm{MPa})\end{array}$ & $\begin{array}{c}\mathrm{S} \\
(\mathrm{mm})\end{array}$ & $\begin{array}{c}\mathrm{Si} \\
(\mathrm{MPa})\end{array}$ & $\begin{array}{c}\mathrm{S} \\
(\mathrm{mm})\end{array}$ & $\begin{array}{c}\mathrm{Si} \\
(\mathrm{MPa}) \\
\end{array}$ & $\begin{array}{c}\mathrm{S} \\
(\mathrm{mm})\end{array}$ & $\begin{array}{c}\mathrm{Si} \\
(\mathrm{MPa})\end{array}$ & $\begin{array}{c}\mathrm{S} \\
(\mathrm{mm})\end{array}$ & $\begin{array}{c}\mathrm{Si} \\
(\mathrm{MPa}) \\
\end{array}$ & $\begin{array}{c}\mathrm{S} \\
(\mathrm{mm})\end{array}$ & $\begin{array}{c}\mathrm{Si} \\
(\mathrm{MPa})\end{array}$ & $\begin{array}{c}\mathrm{S} \\
(\mathrm{mm})\end{array}$ \\
\hline $\begin{array}{l}\text { with } \\
\text { WB } \\
\end{array}$ & 0 & 0.95 & 0.175 & -0.05 & 1.5 & -0.13 & 4.5 & -0.22 & 1.5 & -0.13 & 0.175 & -0.05 & 0 & 0.95 \\
\hline $\begin{array}{l}\text { without } \\
\text { WB }\end{array}$ & 0 & 0.11 & 0 & -0.09 & 2.2 & -0.12 & 4.2 & -0.249 & 2.2 & -0.12 & 0 & -0.09 & 0 & 0.11 \\
\hline
\end{tabular}

Used symbols:

- $\quad$ P1, P2, P3, .., P7 - measuring points or load application points;

- $\quad \mathrm{S} 1, \mathrm{~S} 2, \ldots, \mathrm{S} 7$ - experimentally determined deflections;

- $\quad \mathrm{Si} 1, \mathrm{Si} 2, \ldots, \mathrm{Si} 7$ - stresses determined in points $\mathrm{P} 1, \mathrm{P} 2, \ldots, \mathrm{P} 7$.

On basis of the present paper's approach, a comparative analysis of the theoretical studies and of the experimental tests was performed. The validation of the mathematical model used within the Finite Elements Method analysis (ABAQUS) is performed with help of the comparative analysis of the theoretically established deflections in points P1, P2 ... P7, at an applied load of $1444 \mathrm{~N}$ in points P1, P3 and P4, with the experimentally established deflections.

One established that, in the limit of an admissible error, the finite elements analysis can provide accurate information concerning the stresses and strains field. The finite elements pattern can be used for the dimensional analysis and for the constructive optimization of each crane type structure. On the accomplished model, changes of the constructive conception can be performed, loading to the structure optimization.

One established a study methodology which can be generalized. The emphasized issue is valid for other cranes types, too.

The experimental research program was extremely complex, the final conclusions being of great utility for the increase of the cranes work safety.

For the analytical determination of the structure's answer at imposed excitations, the experimental determination of the matrix of frequency answer functions is required.

\section{CONCLUSIONS}

As a general conclusion of the research, one established that, in the limit of an admissible error, the finite elements analysis can provide accurate information concerning the stresses and strains field. On the accomplished model, changes of the constructive conception can be performed, leading to the structure optimization. The authors have established a study methodology which can be generalized. The emphasized issue is valid for other cranes types, too.

\section{REFERENCES}

[1] Manea, I., Analiza modala experimentala, Editura Universitaria Craiova, 2006.

[2] Radu, N.Gh., Capitole special de rezistenta materialelor, Editura Tehnica Info, Chisinau, 2007.

[3] Vita, I., Sarbu, L., Nuteanu, T., Alexandru, C., Masini de ridicat in constructii, Editura Tehnica, Bucuresti, 1989.

[4] Popescu, M., Studiul macaralelor portal, Teza de doctorat, Universitatea Transilvania din Brasov, 2010. 